\title{
Evaluation of a reel-to-reel atmospheric plasma system for the treatment of polymers
}

\author{
Kate O'Flynn \\ University College Dublin, kate.o-flynn@ucdconnect.ie \\ Vladimir Milosavljevic \\ Technological University Dublin, vladimir.milosavljevic@tudublin.ie \\ Peter Dobbyn \\ University College Dublin, peter.dobbyn@plasmedica.com
}

See next page for additional authors

Follow this and additional works at: https://arrow.tudublin.ie/scschphyart

Part of the Physics Commons

\section{Recommended Citation}

Kate O'Flynn, Vladimir Milosavljević, Peter Dobbyn, Denis P. Dowling, Evaluation of a reel-to-reel atmospheric plasma system for the treatment of polymers, Surfaces and Interfaces, Volume 6, 2017, Pages 162-169, ISSN 2468-0230, DOI: 10.1016/j.surfin.2017.01.005.

This Article is brought to you for free and open access by the School of Physics \& Clinical \& Optometric Science at ARROW@TU Dublin. It has been accepted for inclusion in Articles by an authorized administrator of ARROW@TU Dublin. For more information, please contact arrow.admin@tudublin.ie, aisling.coyne@tudublin.ie, gerard.connolly@tudublin.ie.

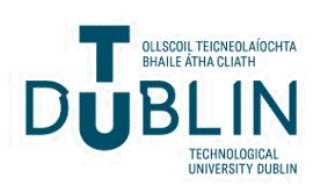




\section{Authors}

Kate O'Flynn, Vladimir Milosavljevic, Peter Dobbyn, and Denis Dowling

This article is available at ARROW@TU Dublin: https://arrow.tudublin.ie/scschphyart/157 


\title{
Evaluation of a reel-to-reel atmospheric plasma system for the treatment of polymers
}

\author{
Kate O’Flynn ${ }^{a}$, Vladimir Milosavljević ${ }^{b}$, Peter Dobbyn ${ }^{c}$, Denis P. Dowling ${ }^{\mathrm{d}, *}$ \\ a Surface Engineering Group, School of Mechanical and Materials Engineering, University College Dublin, Belfield, Dublin 4, Ireland \\ ${ }^{\mathrm{b}}$ BioPlasma Research group, Dublin Institute of Technology, Cathal Brugha Street, Dublin 1, Ireland \\ ' Surface Engineering Group, School of Mechanical and Materials Engineering, University College Dublin, Belfield, Dublin 4, Ireland \\ ${ }^{\mathrm{d}}$ Surface Engineering Group, School of Mechanical and Materials Engineering, University College Dublin, Belfield, Dublin 4, Ireland
}

\section{A R T I C L E I N F O}

\section{Article history:}

Received 10 September 2016

Accepted 16 January 2017

Available online 24 January 2017

\section{Keywords:}

Atmospheric pressure plasma

Reel-to-reel

Polyethylene terephthalate

Surface energy

Optical emission spectroscopy

\begin{abstract}
A B S T R A C T
Plasma treatments are widely used to enhance the surface energy of polymers prior to bonding or the application of functional coatings. This study investigates the performance of a linear atmospheric pressure plasma source for the reel-to-reel treatment of polymer webs. The continuous argon plasma treatments were carried out on $15 \mathrm{~cm}$ diameter polyethylene terephthalate (PET) web substrates using the linear plasma source (Plamax), operating at $13.56 \mathrm{MHz}$. The study investigated how the processing parameters influenced the effectiveness of the plasma treatment in enhancing both the polymer web's water contact angle (WCA) and surface energy (SE). Based on these measurements the plasma treatment was found to yield a homogeneous level of activation across the $15 \mathrm{~cm}$ web, using a treatment speed of $0.9 \mathrm{~m} / \mathrm{min}$. The plasma discharge was monitored using both thermal imaging and optical emission spectroscopy (OES). The latter demonstrated how the oxygen species which diffuse into the argon plasma due to air ingress, were directly correlated with the level of polymer activation.
\end{abstract}

(c) 2017 Elsevier B.V. All rights reserved.

\section{Introduction}

The surface properties of polymers are key to their performance in applications ranging from bonding, biocompatibility, coating adhesion etc. [1,2]. A range of different surface modification techniques have been used as pre-treatments in order to address the low surface energy of polymers, these include; wet chemical modifications [3], flame [4], corona [5,6], ion beam [7] treatments. Of these plasma treatments are particularly widely applied, due to their advantages such as only modifying the surface, while leaving the bulk material unaffected and due to their potential for use in continuous treatments [8]. Polymer exposure to the plasma can result in physical and chemical modifications (particularly the introduction of oxygen functionality), including etching, surface cleaning, crosslinking and activation [9-11]. These plasma treatments can be carried out using both low-pressure [12,13] and atmospheric pressure plasma systems $[11,14]$. Unlike treatments using low-pressure plasmas, those generated at atmospheric pressure can facilitate a more versatile treatments, which allows for the high speed and continuous processing of the substrate

\footnotetext{
* Corresponding author.

E-mail addresses: kate.o-flynn@ucdconnect.ie (K. O’Flynn), vm@dit.ie (V. Milosavljević), peter.dobbyn@plasmedica.com (P. Dobbyn), denis.dowling@ucd.ie (D.P. Dowling).
}

in the absence of a vacuum chamber [15]. A study by Donegan et al. [16] using an rf $\mathrm{He} / \mathrm{O}_{2}$ atmospheric plasma jet source, demonstrated that source input power had a significant effect on the degree of activation on PET. Higher input powers and longer exposure times generally result in a more rapid rate of activation.

There have been a number of publications on the use of atmospheric pressure plasmas for the reel-to-reel treatment of polymers and fibres at as outlined in Table 1 . Two of these studies report on the use of an argon plasma treatments, the first by Bonandini et al. [17] investigated the effect of discharge gas composition for the activation of PET fabrics. It was concluded that the greatest improvement in wettability of the PET fabric was observed using discharged generated using $\mathrm{Ar} / \mathrm{He}$ and $\mathrm{He} / \mathrm{O}_{2}$ gas mixtures. A study by Väänänen et al. [18] used $\mathrm{Ar}$ and $\mathrm{He}$ plasmas to activate polypropylene non-woven fabrics. Based on WCA measurements it was found that the plasma penetrated through a number of layers of the fabric. Examination of the fibres by SEM however demonstrated that over exposure of the fibres to the plasma can result in thermal damage, thus highlighting the need to maintain low surface temperatures.

In this study the performance of a $15 \mathrm{~cm}$ diameter linear argon atmospheric pressure plasma source called Plamax is evaluated for the reel-to-reel treatment of PET webs. The influence of source input power, source to substrate distance, treatment times and the homogeneity of the Ar plasma discharge was examined using 
Table 1

Example of studies of the use of atmospheric pressure plasma reel-to-reel processing systems for plasma treatment of polymers and natural fibres.

\begin{tabular}{|c|c|c|c|c|}
\hline Author & Ref. & Type of discharge & Processing gas & Substrate \\
\hline Tynan et al. & [19] & Dielectric barrier discharge & $\mathrm{He}, \mathrm{O}_{2}$ & PE and PET \\
\hline Li et al. & [20] & Glow discharge & Compressed Air & PE, PU and nylon \\
\hline Bonandini et al. & [17] & Glow discharge & $\mathrm{He}, \mathrm{Ar}, \mathrm{O}_{2}, \mathrm{~N}_{2} / \mathrm{H}_{2}$, dry air & PET fibres \\
\hline Nisticò et al. & [21] & Glow dielectric barrier discharge & $\mathrm{He}, \mathrm{O}_{2}$ & PP meshes \\
\hline Väänänen et al. & [18] & Dielectric barrier discharge & $\mathrm{He}, \mathrm{Ar}$ & PP nonwoven fabric \\
\hline Rombolà et al. & [22] & Dielectric barrier discharge & $\mathrm{He}$ & PP fabrics \\
\hline Ceria et al. & [23] & Post-discharge & $\mathrm{N}_{2}$ & Wool fabrics \\
\hline
\end{tabular}
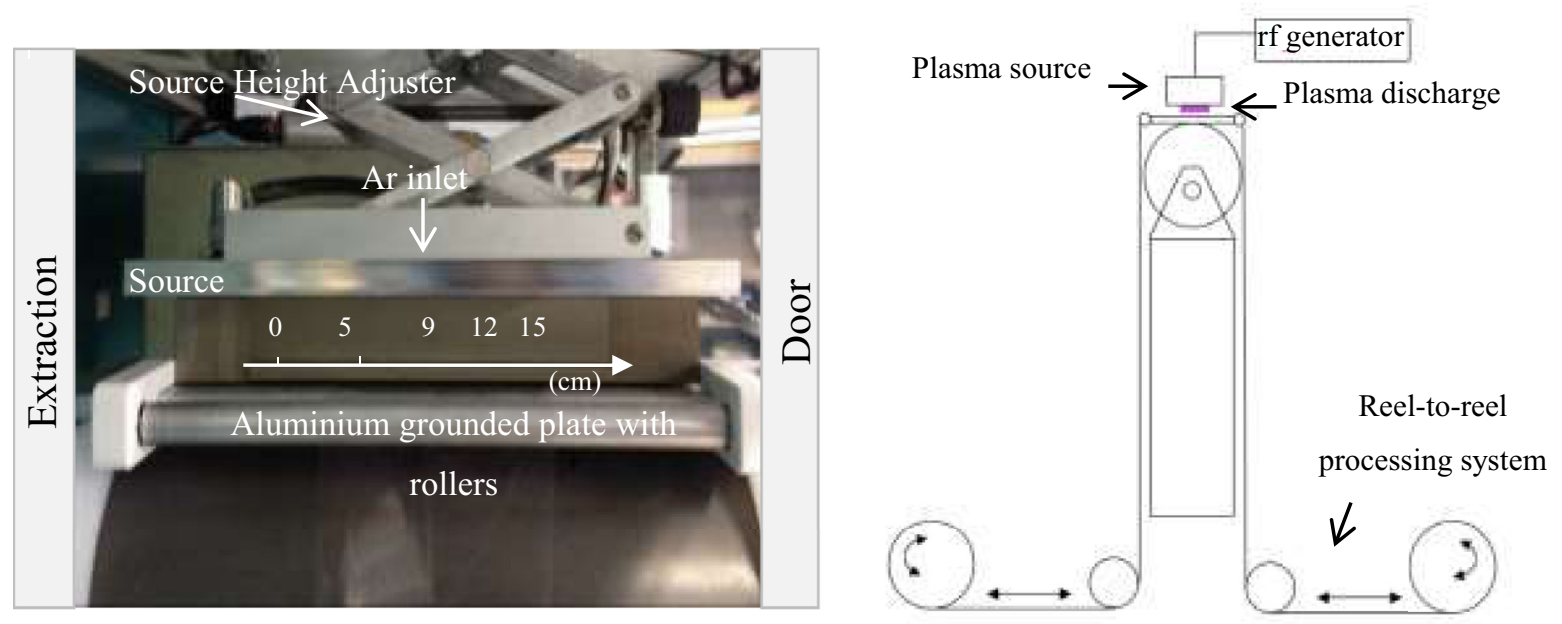

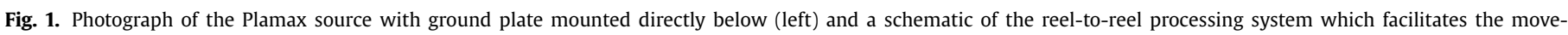
ment of the web under the Plamax source (right).

thermal imaging and optical emission spectroscopy (OES). The latter technique was used to investigate if there was a correlation between the surface energy of the plasma treated polymer and the active species present in the discharge

\section{Experiment and materials}

\subsection{Atmospheric pressure plasma source}

The 13.56 MHz Plamax atmospheric plasma source was manufactured by SPS Co. Ltd. (South Korea) [24]. This source was assembled with a custom-made plasma generator head and connected to an Advanced Energy $13.56 \mathrm{MHz}$ supply which is incorporation with an L-C matching unit. Input powers of up to $200 \mathrm{~W}$ could be supplied to the source. The Plamax source was mounted onto a reel-to-reel system which facilitated the handling of polymer substrates. A photograph of the source along with a schematic of the system is given in Fig. 1. The source counter electrode was a grounded aluminium plate with dimensions of $37 \mathrm{~cm}(\mathrm{~L}), 12 \mathrm{~cm}$ $(\mathrm{W})$ and $1 \mathrm{~cm}(\mathrm{H})$. Two rollers were incorporated onto either side of the plate to prevent snagging of the PET web as it passes underneath the plasma discharge. This in turn was integrated into a reelto-reel web handling system as shown schematically in Fig. 1. The plasma treatment area was $15 \mathrm{~cm}$ in length and approx. $1 \mathrm{~cm}$ in width. As ozone and other species are generated using atmospheric plasma an extraction system is required, this was mounted just to the left of the source shown in the photograph given in Fig. 1. The source orifice to grounded aluminium substrate distance was varied between 2 and $4 \mathrm{~mm}$ using a manual height adjustment system. The speed of the reel-to reel webs could also be adjusted and in this study web speeds of 0.9 to $1.3 \mathrm{~m} / \mathrm{min}$. were investigated.

\subsection{Materials}

Plasma treatment studies were carried out on PET web with thickness of $0.8 \mathrm{~mm}$ and width of $150 \mathrm{~mm}$. $20 \mathrm{~mm} \times 20 \mathrm{~mm}$ test samples were taken from this web for surface energy and contact angle characterisation.

\subsection{Water contact angle (WCA) and surface energy measurements}

WCA were determined using a Dataphysics Instrument OCA 20 system, using the sessile drop technique. The contact angle measurements were calculated using the digital images of the droplets on the substrate, these were imaged using a charged couple device (CCD) camera. Surface energy calculations were determined using three different liquids: deionised water, diiodemethane and ethylene glycol. The liquids were selected to calculate the polar (water) and dispersive forces (diiodemethane) on the surface. The droplets $(1 \mu \mathrm{l})$ was allowed to rest on the surface for approx. $5 \mathrm{~s}$ before contact angles were measured. The Owens-Wendt-Rabel-Kaelble (OWRK) method was used to measure the water contact angle and surface energy of plasma activated polymers [1,25]. The WCA and SE measurements of the polymer web were taken at five positions $(0,5,9,12,15 \mathrm{~cm})$ along the PET web as shown in Fig. 1.

\subsection{Thermal measurements}

Infra-red thermal imaging of the ground aluminium plate mounted $2 \mathrm{~mm}$ below the plasma source were obtained (in the absence of the polymer web) using an InfraTec VarioCAM high resolution thermographic camera. The instrument has a spectral range of $7.5-14 \mu \mathrm{m}$ in the $0-100{ }^{\circ} \mathrm{C}$ [12]. The thermal images were obtained in real time, using IRBIS software. 


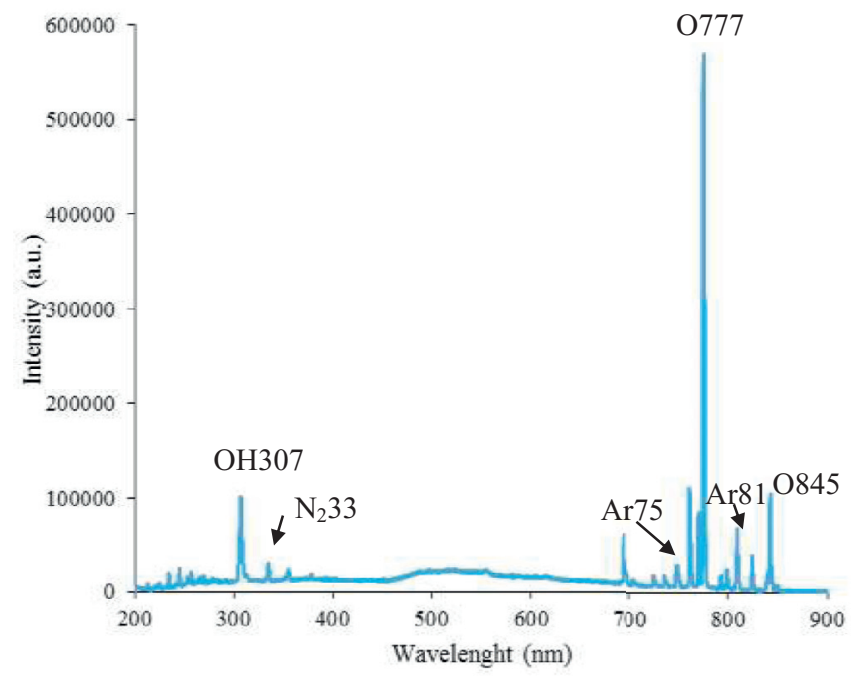

Fig. 2. Typical OES spectrum obtained using the Plamax source (Plasma conditions; Ar 10 l/min, $50 \mathrm{~W}$, integration time $450 \mathrm{~ms}$ ).

\subsection{Optical emission spectroscopy}

The optical emission from the plasma discharge was monitored using an Ocean Optics spectrometer. The USB4000 UV/VIS spectrometer covers the $200-850 \mathrm{~nm}$ regions, with a resolution of 1.2 $\mathrm{nm}$ full width at half maximum (FWHM). All measurements were carried out between the Plamax source orifice and the ground plate mounted $2 \mathrm{~mm}$ below. A qualitative overview of the plasma chemistry was obtained by analysing the emission intensities resulting from different excitation and ionisation processes in the plasma [26]. The species intensities were determined by integrating the area under the emission peak. The integration time, in the range of 50 to $450 \mathrm{~ms}$, was selected (depended on an intensity of the recorded spectral emissions). Comparison among different spectral intensities was achieved by dividing the integration time by the recorded intensities values.

Fig. 2 provides an example of a typical OES spectrum of an Ar plasma, generated using the Plamax source. An atmospheric pressure plasma discharge generated in open air is generally affected by the ingress of ambient air, and as a result reactive nitrogen species and reactive oxygen species can be present in the OES spectrum [27]. The $\mathrm{N}_{2}$ peak at $337 \mathrm{~nm}$ is the 'indicator' of nitrogen diffusion from ambient air. Atomic oxygen spectral emission peaks are observed at 777 and $845 \mathrm{~nm}$ [28]. The $\mathrm{OH}$ spectral emission at $307 \mathrm{~nm}$ is associated with the dissociation of water molecules, which have also diffused from the ambient air. A number of the argon spectral lines are also presence, such as neutral argon spectral emission at $750 \mathrm{~nm}$.

\section{Results and discussion}

The results of this reel-to-reel source evaluation study is divided into three sections, the first outlines the results of thermal imaging measurements, the second evaluates how plasma processing parameters such as input power, source to substrate distance and treatment time influence the level of activation of PET webs. The third section details the measurements of the atomic and molecular species in the linear plasma discharge using OES.

\section{Thermal imaging}

An infrared thermography imaging study was carried out of the Plamax source and aluminium counter electrode. As expected, with an increase in power the temperature of the aluminium plate increased. The effect of altering the input power from 50 to 120 and then to $150 \mathrm{~W}$ was to yield an increase in temperature from 25 to $33^{\circ} \mathrm{C}$. The maximum temperature obtained on the counter electrode after $5 \mathrm{~min}$ of plasma exposure was $33^{\circ} \mathrm{C}$ (at $150 \mathrm{~W}$ ), with a variation of only $\pm 1^{\circ} \mathrm{C}$ across the $15 \mathrm{~cm}$ wide electrode (Fig. 3 ).

\section{Plasma activation of PET webs}

The effect of varying plasma processing parameters on the water contact angle and surface energy of PET was evaluated. The flow rate of $\mathrm{Ar}$ was fixed at $10 \mathrm{l} / \mathrm{min}$ throughout the study, as this yielded a visibly homogenous discharge. The input power was varied between 50 and $200 \mathrm{~W}$, and the source to the grounded aluminium substrate distance was fixed at $2 \mathrm{~mm}$. The reel-to-reel system web speed was varied in the range of 0.9 to $1.3 \mathrm{~m} / \mathrm{min}$. At these speeds the length of exposure time of the PET to the plasma ranged from approximately 13 to $5 \mathrm{~s}$. At the higher web processing speeds under the conditions used, significant levels of air were pulled into the discharge as the web was moved through the discharge, resulting in partial plasma quenching. For this reason, the lowest web speed of $0.9 \mathrm{~m} / \mathrm{min}$ was maintained for the polymer treatment studies.

The effect of varying the input power in the range from 50 to $200 \mathrm{~W}$ is demonstrated in Fig. 4. As expected, with increasing power there was a more effective level of polymer activation. The PET WCA decreased from $92^{\circ}$ to $47^{\circ}$ at the $200 \mathrm{~W}$ input power and a treatment time of approx. $13 \mathrm{~s}$.

The source to substrate (electrode) working distance was varied between 2 and $4 \mathrm{~mm}$ with a fixed input power of $200 \mathrm{~W}$. It was observed that at the working distances of both 2 and $3 \mathrm{~mm}$ the most stable plasma distance was observed across the $15 \mathrm{~cm}$ treatment length. Increasing the working distance to $4 \mathrm{~mm}$, however resulted in a significant reduction in plasma stability particularly at the edges of the treatment area. As expected, based on the WCA and SE measurements the effectiveness of the source for the plasma activation of the web decreased as the working distance increased above $2 \mathrm{~mm}$ (Fig. 5). In addition to a potential decrease in discharge intensity with larger working distances a further issue is that the larger working distance may introduce higher volumes of the atmospheric gases such as oxygen and nitrogen, into the argon plasma partially quenching it and thus reducing its treatment efficiency [29].

After the preliminary scoping study, a more in-depth study was carried out to examine the effect of input power and treatment time on the plasma activation of PET at five points along the 15 $\mathrm{cm}$ length of the linear discharge. The latter measurements were obtained at the $0,5,12$ and $15 \mathrm{~cm}$ positions as demonstrated in Fig. 1. These positions were selected in order to determine the difference in discharge homogeneity across the linear source. At each position, WCA and SE were recorded at varying input powers; 50, 120 and $150 \mathrm{~W}$ and 1,2 and 3 passes of the web under the discharge.

The reproducibility of the WCA measurements across the $15 \mathrm{~cm}$ dimeter PET web is enhanced with 2 and 3 passes compared with 1 pass, as demonstrated in Table 2 . The variation at the five points investigated is lower as the number of activation passes increases.

\section{Optical emission spectroscopy}

OES measurements were recorded at input powers of 50 , 120 and $150 \mathrm{~W}$, at the positions of 0 and $9 \mathrm{~cm}$, along the linear 


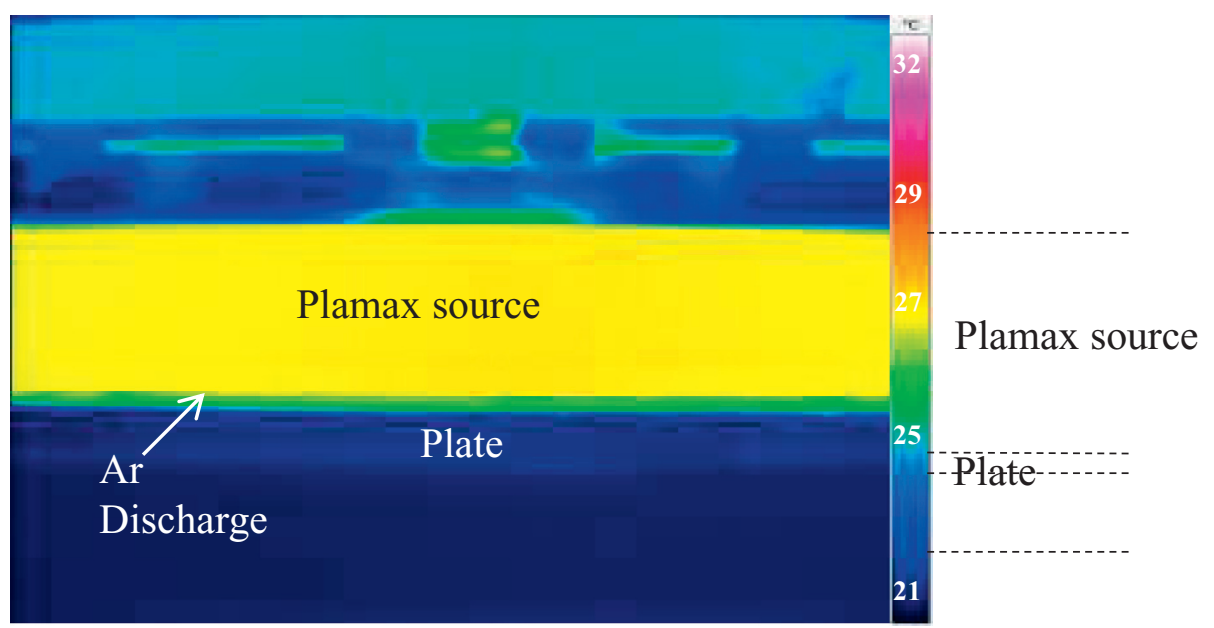

Fig. 3. Thermographic image of the Plamax source positioned $2 \mathrm{~mm}$ above the ground aluminium plate.

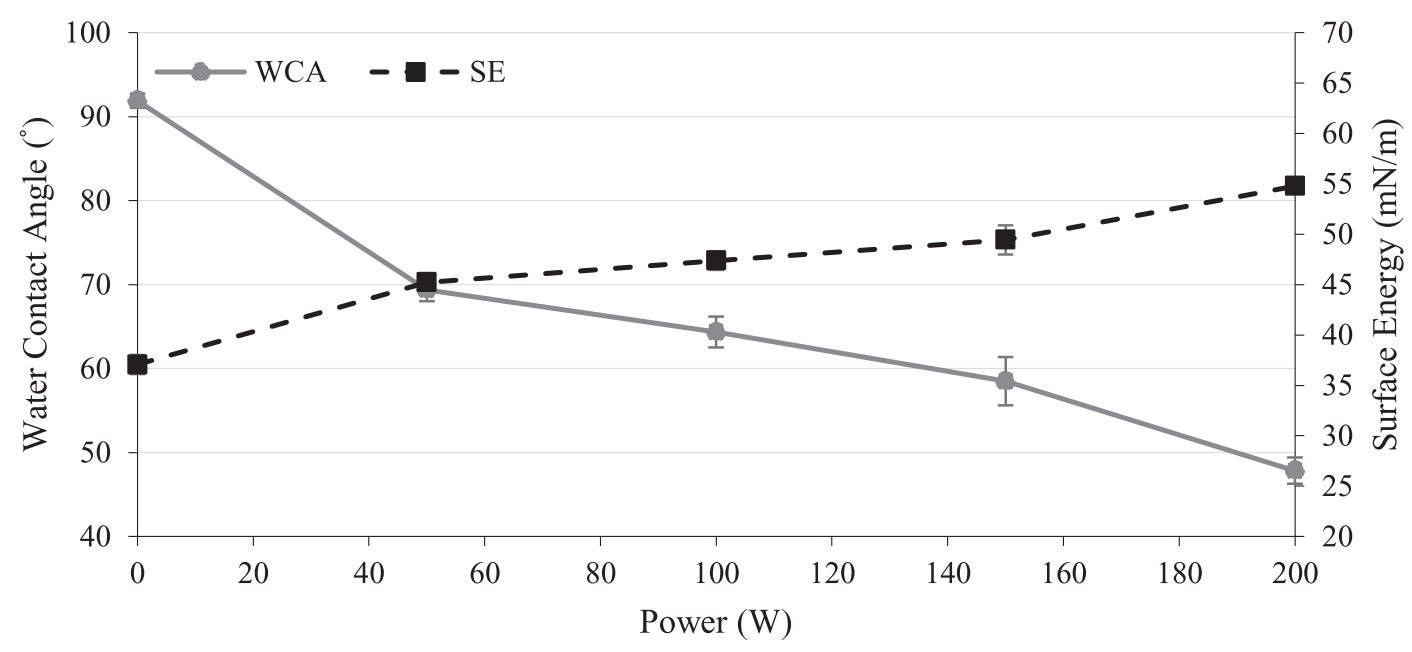

Fig. 4. The effect of input power on the water contact angle and surface energy of the plasma treated PET substrate, at a fixed working distance of 2 mm.

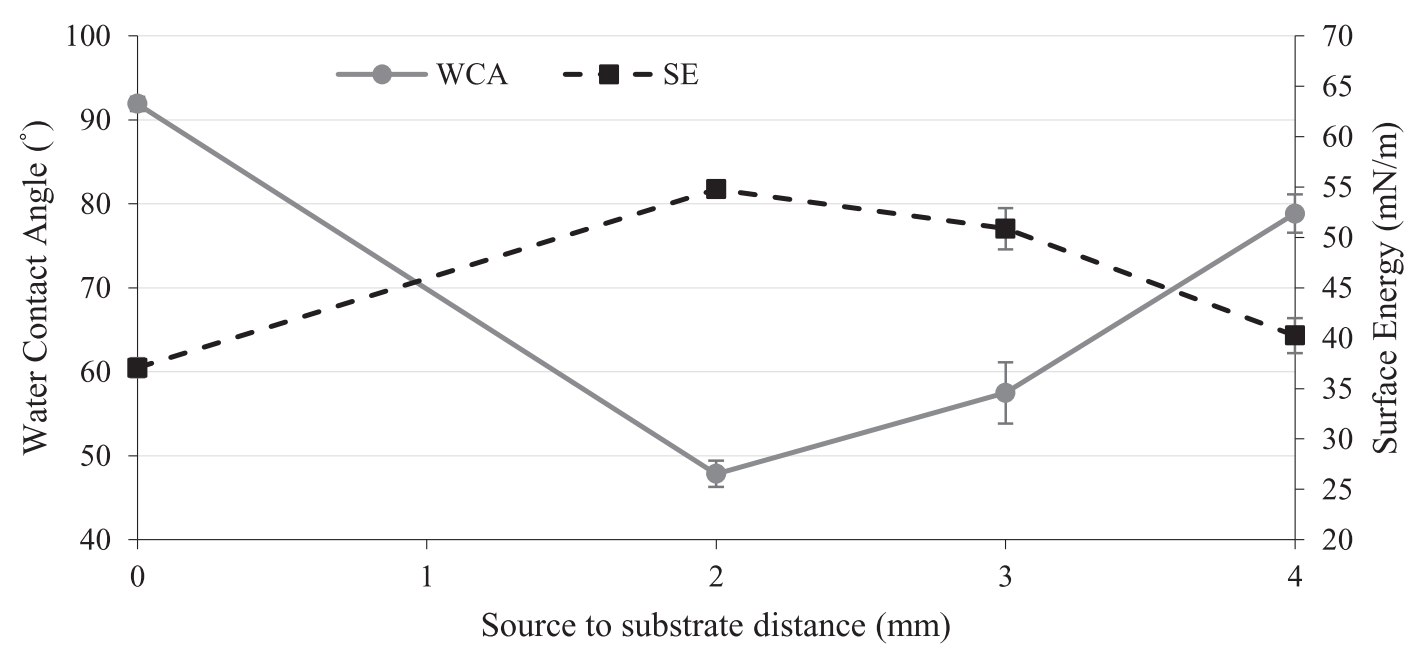

Fig. 5. The effect of source to substrate distance on the water contact angle and surface energy of the plasma treated PET substrate, using an input power of $200 \mathrm{~W}$.

discharge. The spectra were obtained immediately after the plasma was ignited, as well as every $10 \mathrm{~s}$ over a $3 \mathrm{~min}$ period, in the absence of the PET web. From the OES spectra obtained in the range $200-850 \mathrm{~nm}$, peaks associated with six atomic and molecular species were observed. These peaks were identified based on previous studies which reported on atmospheric Ar plasmas
[29]. Argon ( $\operatorname{Ar}$ I) emission intensities are observed at $\lambda=750$ $\mathrm{nm}$ (Ar750) and $811 \mathrm{~nm}$ (Ar811). The non-argon species indicate that ambient air has diffused into the plasma discharge include; nitrogen $\left(\mathrm{N}_{2}\right)$ molecules at $\lambda=337 \mathrm{~nm}\left(\mathrm{~N}_{2} 337\right), \mathrm{OH}$ radical at $\lambda=307 \mathrm{~nm}(\mathrm{OH} 307)$ and oxygen (O I) species at $\lambda=777 \mathrm{~nm}(\mathrm{O} 777)$ and $\lambda=845 \mathrm{~nm}(0845)$. 
Table 2

Water contact angle and surface energy measurements of untreated and plasma treated PET substrates at the positions indicated under the discharge. The plasma treatments were carried out using an input power of $150 \mathrm{~W}$ for 1,2 and 3 passes under the source, as shown.

\begin{tabular}{|c|c|c|c|c|c|c|}
\hline Position of PET $(\mathrm{cm})$ & WCA $\left(^{\circ}\right) 1$ pass & $\mathrm{SE}(\mathrm{mN} / \mathrm{m}) 1$ pass & WCA $\left(^{\circ}\right) 2$ pass & $\mathrm{SE}(\mathrm{mN} / \mathrm{m}) 2$ passes & WCA $\left({ }^{\circ}\right) 3$ pass & $\mathrm{SE}(\mathrm{mN} / \mathrm{m}) 3$ passes \\
\hline Untreated & $92( \pm 1)$ & $37( \pm 1)$ & $92( \pm 1)$ & $37( \pm 1)$ & $92( \pm 1)$ & $37( \pm 1)$ \\
\hline 0 & $56( \pm 2)$ & $51( \pm 2)$ & $52( \pm 1)$ & $54( \pm 1)$ & $47( \pm 1)$ & $56( \pm 1)$ \\
\hline 5 & $59( \pm 1)$ & $49( \pm 1)$ & $52( \pm 1)$ & $53( \pm 1)$ & $47( \pm 2)$ & $56( \pm 1)$ \\
\hline 9 & $58( \pm 1)$ & $50( \pm 1)$ & $51( \pm 2)$ & $54( \pm 2)$ & $47( \pm 2)$ & $56( \pm 1)$ \\
\hline 12 & $55( \pm 2)$ & $51( \pm 1)$ & $50( \pm 2)$ & $55( \pm)$ & $45( \pm 2)$ & $57( \pm 1)$ \\
\hline 15 & $58( \pm 1)$ & $50( \pm 1)$ & $50( \pm 2)$ & $55( \pm 1)$ & $46( \pm 1)$ & $57( \pm 1)$ \\
\hline
\end{tabular}

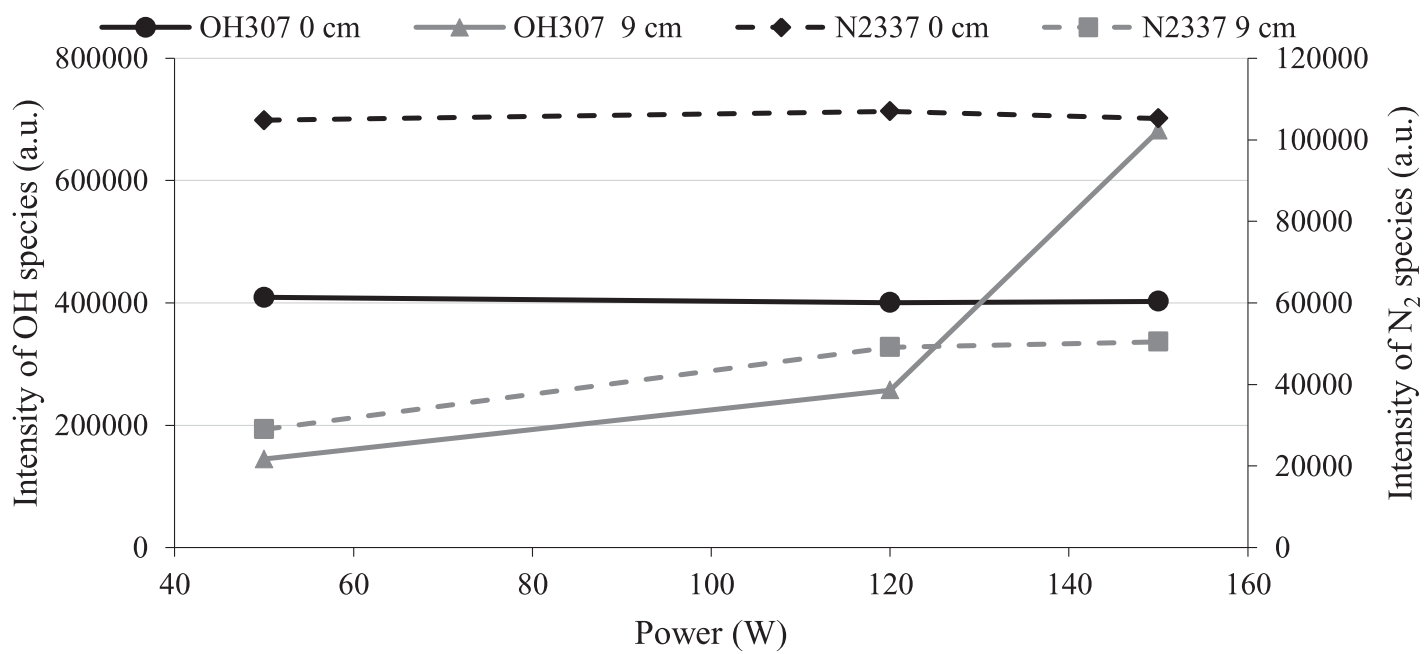

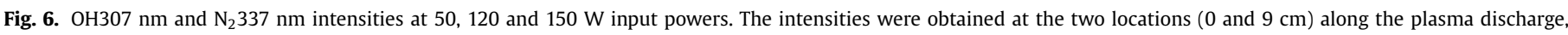
immediately after plasma ignition.

The OES spectra for the following species are discussed in the next three sections; (a) species presence due to the ambient air - $\mathrm{OH}$ and $\mathrm{N}_{2}$, (b) the species relating to the Ar carrier gas - Ar I (atomic argon) and lastly (c) the oxygen species - 0777 and 0845, presence also due to the ambient air.

\section{1. $\mathrm{OH} 307$ and $\mathrm{N}_{2} 337$ spectral emission intensities}

The effect of input power on the emission intensities of $\mathrm{OH}$ 307 and $\mathrm{N}_{2} 337$ species is demonstrated in Fig. 6. It was found that at position $0 \mathrm{~cm}$ the intensities of both $\mathrm{OH} 307$ and $\mathrm{N}_{2} 337$ remained constant as the input power increased. The system air extraction equipment orifice is located close to the $0 \mathrm{~cm}$ position. This extraction may be drawing Ar gas from the source and thus having the effect of reducing the amount of oxygen molecules in the discharge in this region due to air ingress. This trend, however, was not observed for the $\mathrm{OH}$ and $\mathrm{N}_{2}$ intensities recorded at the 9 $\mathrm{cm}$ position, along the plasma discharge (Fig. 6). Their intensities were found to increase at higher input power. Due to the ingress of air the environment at position $9 \mathrm{~cm}$ can thus be considered to be relatively unstable compared with that at the $0 \mathrm{~cm}$ position. The fluctuation in the intensity of both the OH307 and $\mathrm{N}_{2} 337$ peaks between the two positions was investigated. It was observed that the intensities of $\mathrm{OH} 307$ and $\mathrm{N}_{2} 337$ fluctuated $21 \%$ and $27 \%$ respectively. These fluctuations are relatively large, indicating that between the two measurement positions there was variances in these species intensities. It is important to stress there is a significant difference in the energy of upper levels for these two species. Namely, the upper energy levels for emission $\mathrm{OH} 307$ and $\mathrm{N}_{2} 337$ are $4.17 \mathrm{eV}$ and $11.03 \mathrm{eV}$, respectively [30]. The large difference in these energies would be responsible for the difference in intensity observed at $9 \mathrm{~cm}$. The increase of $\mathrm{OH} 307$ intensity can only be explained by taking into account a shift in the electron energy distribution function (EEDF) [31]. The EEDF is objective of this study and its results at the end of this section is presented. The resonant energy transfer among the different plasma species always take place with the highest probability. Therefore, the shift of EEDF towards the lower mean electron energy would leads to increase only the $\mathrm{OH} 307$ intensity, and not the $\mathrm{N}_{2} 337$ intensity (since it requires much higher energy, i.e. $11 \mathrm{eV}$ ).

\subsection{Argon spectral emission intensities}

The intensity of both Ar spectral lines, Ar750 and Ar811, have very similar emission intensities however the emission intensity is higher at the position $9 \mathrm{~cm}$, as shown in Fig. 7. The location of the Ar gas inlet may be influencing (temporally and spatially) the gas volumes along the plasma discharge. As the gas inlet is closer in proximity to the position at $9 \mathrm{~cm}$ (Fig. 1), this may be influencing the gas volume at this location, which results in an increase in $\mathrm{Ar}$ emission intensities and less dilution by ambient air. Despite this observation, the fluctuations of the argon spectral emissions is very low, $4 \%$ and $2 \%$ for Ar750 and Ar811, respectively. Thus demonstrating a stable Ar input across the two points measured in the discharge, i.e. domination of argon (carrier gas) emission over ambient air species. The Ar750 upper energy level is populated by direct electron excitation from the ground state. This process requires a high energy, and with increase of the power (Fig. 7) and concentration of argon (position $9 \mathrm{~cm}$ ), the Ar750 signal also increases.

\subsection{Oxygen spectral emission intensities}

Similar to the trends observed for the argon spectral emissions, the intensities of the oxygen species were also found to increase with input power, and the intensities for both 0777 and 0845 


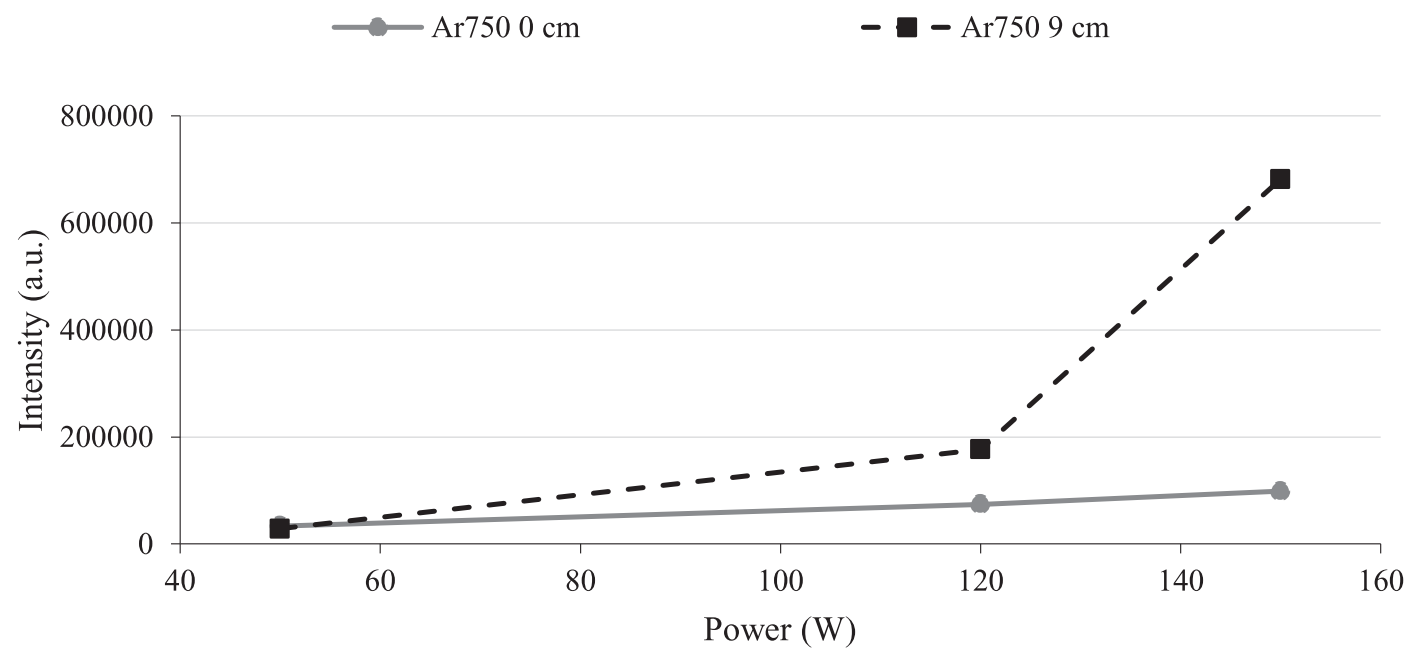

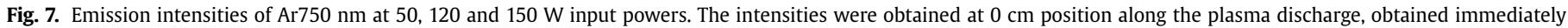
after plasma ignition.

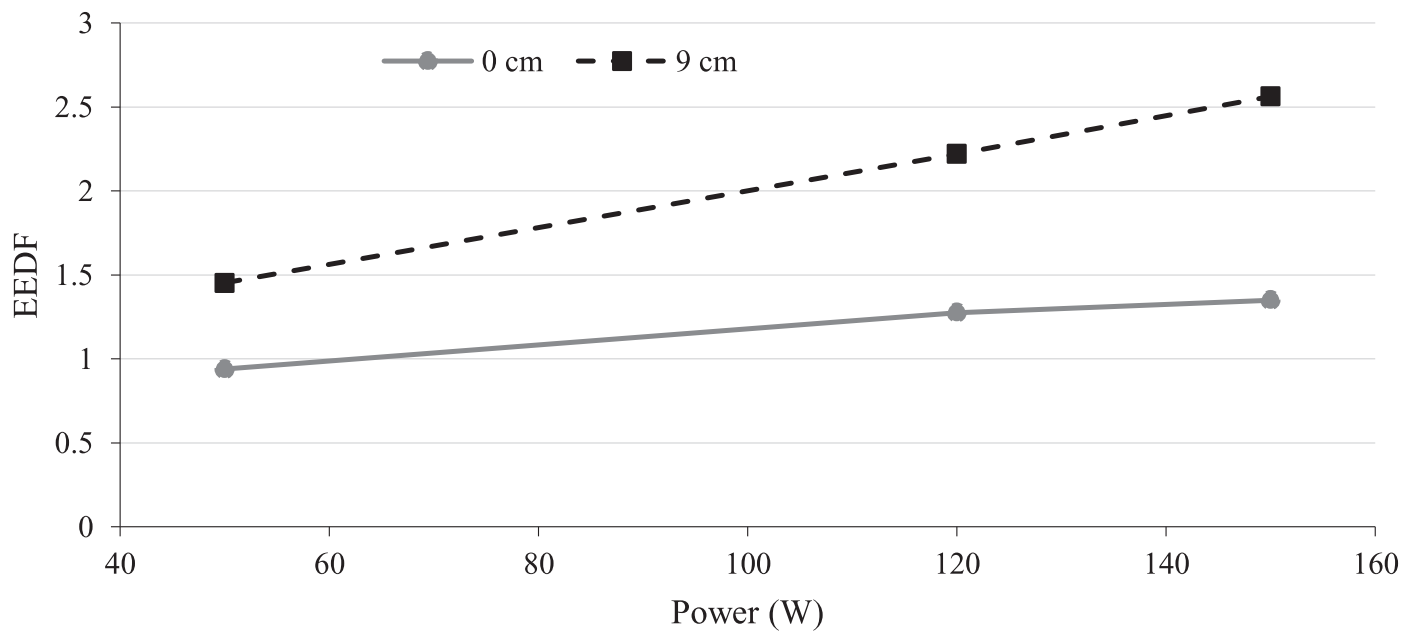

Fig. 8. EEDF curve based on Ar811 and Ar750 spectral emissions.

species were higher at position $9 \mathrm{~cm}$. As the atomic oxygen found in the plasma discharge is typically associated with the ambient air, a similar situation as outlined for the $\mathrm{OH}$ and $\mathrm{N}_{2}$ species is most likely occurring for the 0777 and 0845 species. The extraction position near the $0 \mathrm{~cm}$ could be creating an environment which is minimizing the amount of oxygen and nitrogen molecules in the air, which is resulting in a reduction in oxygen emission intensities.

The electron energy distribution function (EEDF) is important when understanding the plasma kinetics of the plasma source [31]. The emission intensity of the Ar750 specie is created by electron excitation from the ground level. This spectral line is sensitive to the high-energy section of the EEDF, while Ar811 species in contrast are sensitive to lower energy electrons. A change in the EEDF is indicated by a change in the ratio of the Ar811 and Ar750 emission intensities. It is probable that the shift from the dominant Ar emission intensity from 811 to $750 \mathrm{~nm}$ is as a result of changes in the EEDF. This means that the intensity of one spectral line decreases, while the other increases. This is as a result of differences in the electron energy threshold between the excitation level $(13 \mathrm{eV})$ and the metastable/resonance levels $(2 \mathrm{eV})$. The excitation states from the different initial states relate to different parts of the EEDF. This is observed when investigating the energy dependence of the integrand for the excitation from the ground state and their expressions for excitation from the metastable/resonance level from $2 \mathrm{p}^{9} \rightarrow 1 \mathrm{~s}^{5}$ (Ar811) emission and for $2 \mathrm{p}^{1} \rightarrow 1 \mathrm{~s}^{2}$ (Ar750). In general, the $2 \mathrm{p}^{1} \rightarrow 1 \mathrm{~s}^{2}$ transition of Ar750, as it dominated by ground level excitation and has only slight radiation-trapping correction. Electrons with energy in the ranges between 13 to $25 \mathrm{eV}$ are relevant for the excitation of the ground state atoms into the $2 \mathrm{p}^{1}$ level. The excitation out of the $1 \mathrm{~s}^{5}$ level, however, use electrons of lower energies from $2 \mathrm{eV}$ up to higher energies of $15 \mathrm{eV}$. The significant amount of radiation observed is due to the excitation from the $1 s^{5}$ levels [31]. The $2 \mathrm{p}^{1}$ levels are populated by excitation from the ground, metastable and resonance levels, and as such the relative ratio of low to high energy electrons in the plasma can be obtained by investigating the emissions $2 \mathrm{p}^{9} \rightarrow 1 \mathrm{~s}^{5}$ and $2 \mathrm{p}^{1} \rightarrow 1 \mathrm{~s}^{2}$ emission lines. For atmospheric pressure plasma in particular, the dissociative recombination with molecular ions remove low-energy electrons [31]. This causes the low-energy segment of the electron energy distribution to be lower, when oxygen or/and nitrogen (i.e. atmospheric gases from ambient air) is mixed with argon. Therefore, the ratio of Ar811/Ar750 is lower in a gas mixture than in pure $\mathrm{Ar}$ gas. Due to the slope and the direction of the slope of the two curves (Fig. 8), it is possible the maximum has not been reached, and the observed curves are indicating a low-energy tail of the EEDF. 


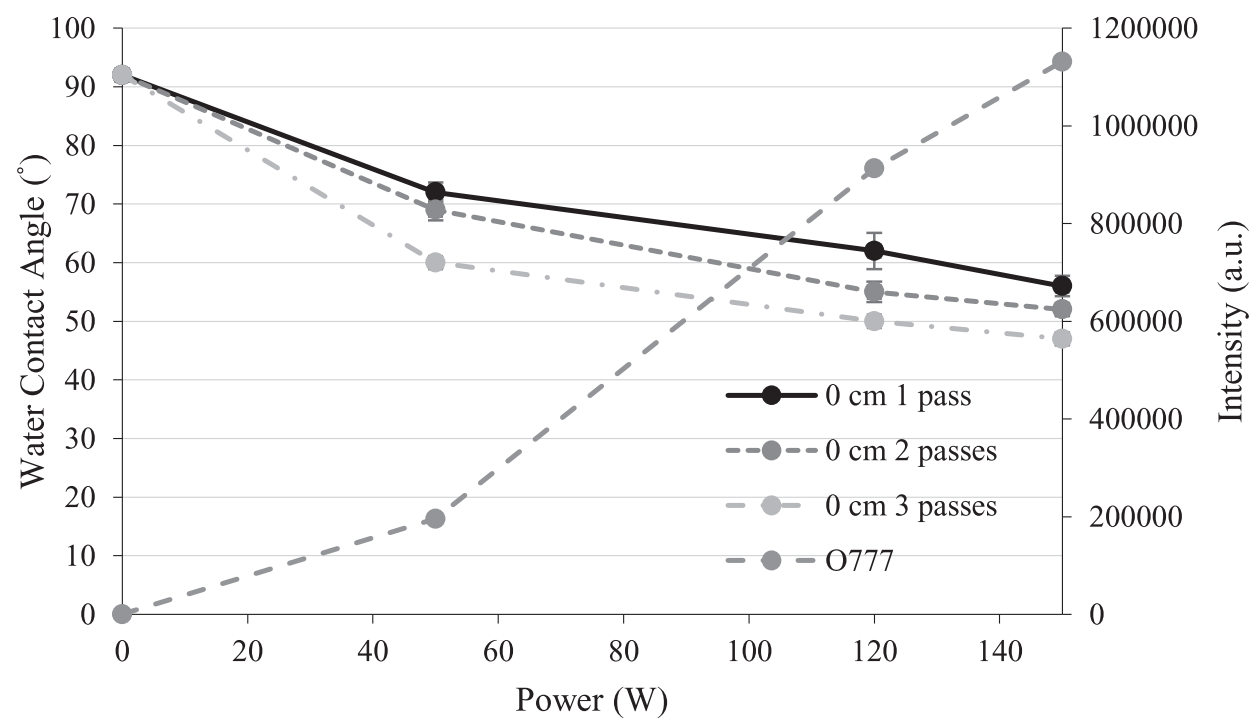

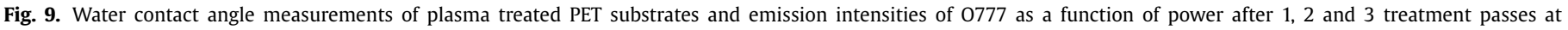
position $0 \mathrm{~cm}$.

It was attempted to correlate the WCA measurements obtained on the treated PET substrates as detailed earlier with changes in peak intensities obtained from the OES measurements. From this study it was concluded that the improved surface properties observed on the plasma treated PET substrates could in particular be attributed to the atomic oxygen-based species, rather than the $\mathrm{Ar}, \mathrm{N}_{2}$ or $\mathrm{OH}$ species. This conclusion was drawn from the observation in the OES spectra that the intensities of these latter species were found to be relatively insensitive to the change in power over the $0-150 \mathrm{~W}$ range studies. In contrast in the case of atomic oxygen there was a significant increase in the emission intensity with increasing power (Fig. 9). In this latter figure the intensities of 0777 was normalised using the maximum intensities of $1,200,000$ counts.

The relationship between the decreasing WCA values of the treated PET substrate are and the increase in oxygen species intensities is demonstrated in Fig. 9. A similar spectral emission was observed for 0845, however the intensities for 0777 was 6 times greater than those observed at 0845 (because of the spectrometer quantum efficiency). As a result, it can be concluded that 0777 and O845 have a similar spectral response. Both oxygen species can be formed by the direct excitation from the ground state. There is, however another possible channel for the formation of 0777 , which is molecular dissociation [31]. 0845 cannot be formed by this route however [32], and based on both species having similar spectral "fingerprint", it is evident that molecular dissociation of oxygen did not play a role in the creation of the 0777 emission. The correlation between the WCA and the OES data indicate the significant role of the oxygen species in the discharge influencing the surface properties of the PET, which results the increase of the SE and polar contributions of the plasma treated substrates. This result is supported by the conclusion obtained by other authors For example, a study by Huang et al. [33] investigated the atmospheric argon plasma treatments on static PET substrates using a cyclonic atmospheric pressure plasma jet source. It was concluded by use of OES that the interaction of the oxygen species was important for enhancing polymer surface properties.

\section{Conclusion}

The focus of this study has been to evaluate the performance of the linear rf atmospheric pressure Plamax source for the reel- to-reel activation of PET webs. The suitability of this source for the plasma treatment of polymers was demonstrated using the thermal imaging measurements. These demonstrated that during treatment the maximum temperature of $33^{\circ} \mathrm{C}$ at was achieved after 5 min treatment at $150 \mathrm{~W}$. The temperature was found to be homogeneous across the treatment area. It was also demonstrated based on both WCA and SE measurements that the level of polymer activation was homogeneous across its $15 \mathrm{~cm}$ length. As anticipated higher levels of activation were observed when higher source input powers (up to $200 \mathrm{~W}$ ), 3 treatment passes and a small working distance $(2 \mathrm{~mm})$ were used. OES was used to identify active species in the discharge and it was attempted to correlate if specific active species were more associated with changes in PET wettability. It was concluded that the changes in intensity of the atomic oxygen lines (particular 0777 and 0845), were found to correlate more strongly with higher levels of polymer activation. The intensities of the OES lines for $\mathrm{Ar}, \mathrm{N}_{2}$ and $\mathrm{OH}$ in contrast were found to be less sensitive to changes in plasma processing conditions.

This study demonstrates the effectiveness of the Plamax reel-toreel source for the homogeneous activation of polymer substrates. If continuous web processing was carried out under the conditions used in this study then up to $54 \mathrm{~m} / \mathrm{h}$ would be treated. The correlation between surface activation and oxygen line OES spectral emission indicates its potential as a real time process diagnostic.

\section{Acknowledgements}

The authors would like to acknowledge the support of the MaREI SFI Centre and the IComp Technology Centre for this study.

\section{References}

[1] D.K. Owens, R. Wendt, J. Appl. Polym. Sci. 13 (1969) 1741-1747.

[2] C. Nwankire, V. Law, A. Nindrayog, B. Twomey, K. Niemi, V. Milosavljević, W. Graham, D. Dowling, Plasma Chem. Plasma Process. 30 (2010) 537-552.

[3] A. Kruse, G. Krüger, A. Baalmann, O.-D. Hennemann, J. Adhes. Sci. Technol. 9 (1995) 1611-1621.

[4] M. Strobel, V. Jones, C.S. Lyons, M. Ulsh, M.J. Kushner, R. Dorai, M.C. Branch, Plasmas Polym. 8 (2003) 61-95.

[5] N. Sellin, J.S.d.C. Campos, Mater. Res. 6 (2003) 163-166.

[6] L.A. O'Hare, S. Leadley, B. Parbhoo, Surf. Interface Anal. 33 (2002) 335-342.

[7] H. Dong, T. Bell, Surf. Coat. Technol. 111 (1999) 29-40.

[8] I. Junkar, A. Vesel, U. Cvelbar, M. Mozetič, S. Strnad, Vacuum 84 (2009) 83-85.

[9] M. Shenton, G. Stevens, N. Wright, X. Duan, J. Polym. Sci. Part A 40 (2002) 95-109. 
[10] P. Slepička, N.S. Kasálková, E. Stránská, L. Bačáková, V. Švorčík, Express Polym. Lett. 7 (2013).

[11] J.-H. Kim, G. Liu, S.H. Kim, J. Mater. Chem. 16 (2006) 977-981.

[12] V.J. Law, J. Mohan, F.T. O’Neill, A. Ivankovic, D.P. Dowling, Int. J. Adhes.. Adhes. 54 (2014) 72-81.

[13] D.P. Dowling, F.T. O’Neill, S.J. Langlais, V.J. Law, Plasma Processes Polym. 8 (2011) 718-727.

[14] Z. Fang, J. Yang, Y. Liu, T. Shao, C. Zhang, Plasma Sci. IEEE Trans. 41 (2013) 1627-1634.

[15] Y. Kusano, H. Mortensen, B. Stenum, P. Kingshott, T.L. Andersen, P. Brøndsted, J.B. Bilde-Sørensen, B.F. Sørensen, H. Bindslev, Plasma Processes Polym. 4 (2007) S455-S459.

[16] M. Donegan, V. Milosavljević, D.P. Dowling, Plasma Chem. Plasma Process. 33 (2013) 941-957.

[17] L. Bonandini, N. Barbero, K. Costabello, C. Pavan, F. Parisi, G. Viscardi, ChemSusChem 3 (2010) 591-596.

[18] R. Vaananen, P. Heikkila, M. Tuominen, J. Kuusipalo, A. Harlin, AUTEX Res. J. 10 (2010) 8-13.

[19] J. Tynan, D.P. Dowling, G. Byrne, D. Hughes, Int. J. Nanomanuf. 1 (2007) 554-569.
[20] Q. Li, P.P. Tsai, S. Nourgostar, Z. Chen, J.R. Roth, in: Pulsed Power Conference, 2007 16th IEEE International, IEEE, 2007, pp. 372-375.

[21] R. Nisticò, G. Magnacca, M.G. Faga, G. Gautier, D. D’Angelo, E. Ciancio, R. Lamberti, S. Martorana, Appl. Surf. Sci. 279 (2013) 285-292.

[22] G. Rombola, F. Parisi, C. Pavan, D. Dapra, Czech. J. Phys. 56 (2006) B1021-B1028.

[23] A. Ceria, F. Rombaldoni, G. Rovero, G. Mazzuchetti, S. Sicardi, J. Mater. Process. Technol. 210 (2010) 720-726.

[24] S.H. Kim, J.-H. Kim, B.-K. Kang, H.S. Uhm, Langmuir 21 (2005) 12213-12217.

[25] M. Donegan, D.P. Dowling, Surf. Coat. Technol. 234 (2013) 53-59.

[26] S.-J. Park, J.-S. Jin, J. Colloid Interface Sci. 242 (2001) 174-179.

[27] S. Reuter, J. Winter, A. Schmidt-Bleker, H. Tresp, M.U. Hammer, K.-D. Weltmann, IEEE Trans. Plasma Sci. 40 (2012) 2788-2794.

[28] K. Fricke, I. Koban, H. Tresp, L. Jablonowski, K. Schröder, A. Kramer, K.-D. Weltmann, T. von Woedtke, T. Kocher, PloS one 7 (2012) e42539.

[29] Z.M. Ishak, A. Ariffin, R. Senawi, Eur. Polym. J. 37 (2001) 1635-1647.

[30] Y.R.A. Kramida, J. Reader and NIST ASD Team (2016): NIST Atomic Spectra Database (ver. 5.3), 2016

[31] P. Cullen, V. Milosavljević, Prog. Theor. Exp. Phys. 2015 (2015) 063J001.

[32] V. Milosavljević, A. Ellingboe, S. Daniels, Eur. Phys. J. D 64 (2011) 437-445.

[33] C. Huang, Y.-C. Chang, S.-Y. Wu, Thin Solid Films 518 (2010) 3575-3580. 